\title{
Pre-ablation levels of brain natriuretic peptide are independently associated with the recurrence of atrial fibrillation after radiofrequency catheter ablation in patients with nonvalvular atrial fibrillation
}

\author{
Junichiro Miake ${ }^{1}$ - Masaru Kato ${ }^{2} \cdot$ Kazuyoshi Ogura $^{2} \cdot$ Kazuhiko litsuka $^{2} \cdot$ Akihiro Okamura $^{2} \cdot$ Takuya Tomomori $^{2}$. \\ Daiki Tsujimoto $^{2} \cdot$ Masahiko Kato $^{2} \cdot$ Kazuhiro Yamamoto $^{2}$
}

Received: 6 July 2018 / Accepted: 14 September 2018 / Published online: 20 September 2018

(c) The Author(s) 2018

\begin{abstract}
Association between pre-ablation levels of biomarkers of cardiac and endothelial dysfunctions, CHADS2, CHA2DS2VASc, and APPLE scores and the recurrence of atrial fibrillation (AF) after radiofrequency catheter ablation has not been fully studied. A total of 254 patients with nonvalvular AF were prospectively followed for AF recurrence after a single ablation procedure. During a two-year follow-up period, AF recurred in $65(25.6 \%)$ patients. Patients with AF recurrence had significantly greater baseline ln brain natriuretic peptide (BNP) than those without AF recurrence $(P<0.01)$, whereas there were no significant differences in the levels of biomarkers of endothelial dysfunction and points of scoring systems. In the Cox regression analyses, the baseline ln BNP was significantly independently associated with AF recurrence (adjusted $\mathrm{HR}=1.286,95 \% \mathrm{CI}=1.000-1.655, P<0.05$ ). The baseline levels of $\ln \mathrm{BNP}$ were significantly associated with rhythm at blood collection, age, sex, and left atrial diameter, and left ventricular ejection fraction $(P<0.05)$. The subgroup analysis showed a significant interaction on the risk of AF recurrence between ln BNP, sex difference, and rhythm at blood collection ( $P$ for interaction $<0.05$ ). In conclusion, the results suggest that the pre-ablation levels of $\ln \mathrm{BNP}$ are useful to evaluate the risk of AF recurrence after ablation therapy; however, there is a need to be careful while using BNP as a biomarker for the risk of AF recurrence by taking account of the effects of rhythm status at blood collection and sex difference.
\end{abstract}

Keywords Atrial fibrillation $\cdot$ Catheter ablation $\cdot$ Recurrence $\cdot$ Biomarkers $\cdot$ Brain natriuretic peptide

\section{Introduction}

Atrial fibrillation (AF), one of the commonest arrhythmias [1], is associated with an increased morbidity and mortality $[2,3]$. Haïssaguerre et al. have reported that the pulmonary veins are the dominant sources of triggers for initiating $\mathrm{AF}$ in most patients [4]. Catheter ablation of AF with isolation

Junichiro Miake

jmiake@tottori-u.ac.jp

1 Division of Molecular Pharmacology, Department of Pathophysiological and Therapeutic Science, Faculty of Medicine, Tottori University, Yonago 683-8503, Japan

2 Division of Cardiovascular Medicine, Endocrinology and Metabolism, Department of Molecular Medicine and Therapeutics, Faculty of Medicine, Tottori University, Yonago 683-8503, Japan of the pulmonary veins, which has become the standard therapy for symptomatic patients with AF that is refractory to medical therapy [5], is highly effective at curing paroxysmal or persistent AF [6]. However, AF recurs after ablation therapy in some patients and the risk of such recurrence has been difficult to predict [7].

Inflammatory, oxidative stress [8-10] and atrial remodeling $[11,12]$ have been reported as the etiology of AF development. In addition, it has been reported that multiple risk scores and biomarkers considering these etiologies may be predictors of recurrence after atrial fibrillation ablation treatment. The $\mathrm{CHADS}_{2}$ and $\mathrm{CHA}_{2} \mathrm{DS}_{2}$-VASc scores, both of which comprise common cardiovascular risk factors, has been originally developed for predicting stroke and thromboembolism [13]. These scores have been reported to be associated with AF recurrence in patients with paroxysmal AF after a single ablation procedure [14], and with long-term outcomes in patients 
with paroxysmal $\mathrm{AF}$ and persistent $\mathrm{AF}$ after $\mathrm{AF}$ ablation [15]. However, studies on the predictive value of the $\mathrm{CHADS}_{2}$ and $\mathrm{CHA}_{2} \mathrm{DS}_{2}$-VASc scores on the recurrence of AF after ablation had inconsistent results [16]. Then, the APPLE score has been developed to predict AF recurrence after an ablation procedure in patients with paroxysmal and persistent AF. This score comprises five clinical variables such as age, type of $\mathrm{AF}$, renal function, and echocardiographic variables [17]. The APPLE had better prediction of AF recurrence between 3 and 12 months after catheter ablation than $\mathrm{CHADS}_{2}$ and $\mathrm{CHA}_{2} \mathrm{DS}_{2}$-VASc scores [17]. Of biomarkers, brain natriuretic peptide (BNP), an intensively studied biomarker of cardiac dysfunction, has been reported being a predictor of the recurrence of AF $[18,19]$. Biomarkers of endothelial dysfunction caused by inflammatory, oxidative stress, such as inflammation-related leukocyte adhesion molecules (vascular cell adhesion molecule-1 [VCAM1]; intercellular adhesion molecule-1 [ICAM1]; and endothelial cell-leukocyte adhesion molecules-1 [ELAM1]), a physiological endothelial anticoagulant (thrombomodulin [TM]), and a platelet adhesion molecule (von Willebrand factor [VWF]) have been reported to be associated with risk of incident AF [20-24]. However, there were significant heterogeneities between studies to test associations between BNP and the recurrence of AF in metaanalysis studies, and such heterogeneities have not been fully explained $[18,19]$. Moreover, associations between biomarkers of endothelial dysfunction and the recurrence of AF have not been fully studied. Furthermore, associations of the risk scores, biomarkers and atrial remodeling with the recurrence of AF have not been deeply and systematically studied.

In this study, we measured pre-ablation levels of biomarkers of cardiac and endothelial dysfunction, and evaluated scores of $\mathrm{CHADS}_{2}$ and $\mathrm{CHA}_{2} \mathrm{DS}_{2}$-VASc, and APPLE scoring systems in patients with nonvalvular paroxysmal or persistent AF. We then examined associations between these pre-ablation variables and the recurrence of AF after radiofrequency catheter ablation. Moreover, a variable significantly and independently associated with the recurrence of AF was tested for associations with a number of key risk variables such as age, sex, type of AF, history of heart failure, history of hypertension, history of diabetes mellitus, history of stroke or transient ischemic attack, history of coronary or peripheral vascular disease, renal function, LAD, and LVEF [25]. Finally, we performed subgroup analyses and tested interactions for a baseline variable significantly associated with the recurrence of AF.

\section{Methods}

\section{Study cohort and design}

Consecutive patients with nonvalvular paroxysmal or persistent AF who underwent a single catheter ablation from
March 2013 to December 2015 in Tottori University Hospital, Japan were enrolled and followed prospectively for the recurrence of AF after ablation. Paroxysmal AF was defined as self-terminating AF lasting for up to 7 days or AF episodes cardioverted within 7 days, and persistent $\mathrm{AF}$ as $\mathrm{AF}$ lasting between 7 days and 1 year or AF episodes terminated by cardioversion either with drugs or by direct current cardioversion after 7 days or more [5]. Levels of estimated glomerular filtration rate (eGFR) were calculated with the following equation established by the Japanese Society of Nephrology: eGFR $\left(\mathrm{mL} / \mathrm{min} / 1.73 \mathrm{~m}^{2}\right)=194 \times$ serum creatinine level ${ }^{-1.094} \times$ age $^{-0.287}(\times 0.739$ if female).[3] The CHADS 2 score comprised congestive heart failure, hypertension, age $\geq 75$, diabetes mellitus, and stroke/transient ischemic attack and the $\mathrm{CHA}_{2} \mathrm{DS}_{2}$-VASc score comprised congestive heart failure, hypertension, age $\geq 75$ years, diabetes mellitus, stroke/transient ischemic attack, vascular disease, age 65-74 years, and female sex [13]. The APPLE score comprised age $>65$ years, persistent AF, reduced eGFR $<60 \mathrm{ml} / \mathrm{min} / 1.73 \mathrm{~m}^{2}$, left atrial diameter (LAD) $\geq 43 \mathrm{~mm}$, and left ventricular ejection fraction (LVEF) $<50 \%$. The APPLE had better prediction of AF recurrence between 3 and 12 months after catheter ablation than $\mathrm{CHADS}_{2}$ and $\mathrm{CHA}_{2} \mathrm{DS}_{2}$-VASc scores [17]. Patients with one or more of the following were excluded from candidates for ablation of AF in this study: age less than 20 years or over 85 years; cerebral or myocardial infarction within 6 months of onset; uncontrolled heart failure or left ventricular ejection fraction $<40 \%$; severe chronic obstructive pulmonary disease; contraindications to anticoagulants; thrombus formation within the left atrial appendage; LAD $>60 \mathrm{~mm}$; moderate or severe valvular insufficiency or stenosis; connective tissue disease; and active cancer. It was also planned to exclude patients with hypertrophic/dilated cardiomyopathy or old myocardial infarction, end-stage renal disease or on hemodialysis: five patients with hypertrophic cardiomyopathy and six with end-stage renal disease or on hemodialysis were thus excluded. This study was approved by the Ethics Committee of Faculty of Medicine, Tottori University, and conducted in compliance with the ethical principles of the Declaration of Helsinki. Written informed consent was obtained from all individual participants included in the study.

\section{Catheter ablation protocol}

The protocol for catheter ablation of AF has been reported previously [11]. Briefly, prior to the ablation procedure, all patients received effective oral anticoagulation therapy for at least four weeks and underwent transesophageal echocardiography and enhanced cardiac computed tomography for 3D mapping. Antiarrhythmic drugs were discontinued for more than five times their half-lives. Oral anticoagulants were discontinued before the procedure: 
direct oral anticoagulants for one day and warfarin for five days, and replaced with unfractionated heparin until $6 \mathrm{~h}$ prior to the ablation procedure. Bipolar electrograms were continuously recorded on a digital recording system (Labsystem PRO; Bard Electrophysiology, Lowell, MA, USA). A 20-pole three-sited mapping catheter (BeeAT; Japan Lifeline, Tokyo, Japan) was used to record bipolar electrograms of the superior vena cava, right atrium, and coronary sinus. After transseptal puncture, heparin was continuously infused to maintain an activated clotting time of 300-400 s. Two decapolar circular mapping catheters (Lasso; Biosense Webster, Diamond Bar, CA, USA) were located in the pulmonary veins. A $3.5 \mathrm{~mm}$ irrigatedtip ablation catheter (Thermocool; Biosense Webster) was advanced into the LA to achieve bilateral circumferential pulmonary vein isolation with the endpoint of bidirectional conduction block between the LA and pulmonary vein. A point-by-point radiofrequency current was delivered for $30 \mathrm{~s}$ with a power of up to 40 watts and a target temperature less than $43^{\circ} \mathrm{C}$ using a 3D mapping system (CARTO3; Biosense Webster), whereas the power was limited to 20 watts at the site close to the esophagus. After achieving pulmonary vein isolation, a bidirectional conduction blocking line was created at the cavotricuspid isthmus in all patients. The ablation procedure was performed under conscious sedation with continuous monitoring of blood pressure and oxygen saturation.

\section{Blood sample collection and processing}

Blood was sampled from the femoral vein (FV) with an 18 gauge needle prior to the ablation procedure on the day of ablation therapy, placed immediately on ice and centrifuged at $3,000 \mathrm{~g}$ for $15 \mathrm{~min}$ at $4{ }^{\circ} \mathrm{C}$. The resultant serum or plasma was aliquoted to different tubes to avoid repeated freeze-thaw cycles and stored at $-80^{\circ} \mathrm{C}$ till use. Serum soluble ELAM1 (sELAM1; ng/mL), soluble VCAM1 (sVCAM1; ng/mL), and soluble ICAM1 (sICAM1; ng/ $\mathrm{mL}$ ) were measured by enzyme-linked immunosorbent assay (ELISA; R\&D systems, Minneapolis, MN, USA); plasma VWF activity (\%) by latex agglutination immunoassay (LAIA; Siemens Healthcare Diagnostics Products GmbH, Marburg, Germany); serum soluble TM (sTM; FU/mL) by ELISA (Kyowa Pharma Chemical, Takaoka, Toyama, Japan); plasma BNP (pg/mL) by chemiluminescent enzyme immunoassay (CLEIA; Fujirebio, Shinjuku, Tokyo, Japan). The within-run reproducibility was $<8 \%$ for ELISAs and CLEIA and $<20 \%$ for LAIA. All assays were performed by investigators who were blinded to all clinical information about the participants.

\section{Clinical outcomes and follow-up}

The primary clinical outcome was recurrent AF lasting over $30 \mathrm{~s}$ off antiarrhythmic drugs. Episodes during the blanking period of the first 90 days after the ablation procedure were not considered as recurrences [5]. All patients underwent continuous ECG monitoring for 3 days following the procedure until discharge. Follow-up checks were performed $1,2,3,6,9,12,16,20$, and 24 months after the ablation procedure and comprised physical examination, 12-lead electrocardiogram, and 24-h Holter monitoring. Patients were instructed to self-monitor their pulses daily and report any irregularity of pulse immediately, at which point event monitoring or 14-day Holter monitoring was performed. Oral anticoagulant therapy was continued in all patients with $\mathrm{CHA}_{2} \mathrm{DS}_{2}$-VASc scores of two or more points after the procedure, but discontinued at 6 months in those whose scores were less than 2 points.

\section{Statistical analysis}

Categorical data are presented as frequency (percentage [\%]) and were compared with Fisher's exact test. Continuous data are presented as mean (standard deviation [SD]) or as median (interquartile range) for skewed distributions. Normality was tested with the Kolmogorov-Smirnov test. Normally distributed continuous variables were compared using the independent Student's $t$ test and skewed data using the non-parametric Mann-Whitney $U$ test. Analyses were performed after natural logarithmic transformation (ln) of skewed biomarkers. Freedom from AF was reported as crude event rates and by means of a time-to-event analysis using the Kaplan-Meier method. Variables with $P$ value $<0.10$ in the group comparison were further evaluated by the Cox proportional hazards regression analyses to determine their associations with the recurrence of AF. The variables with $P$ value $<0.10$ in the univariate Cox proportional hazards regression analysis were further evaluated by the multivariate Cox proportional hazards regression analysis. Multiple regression analysis via the forced entry procedure was performed to test correlations of a normally distributed continuous variable with other variables. Statistical analyses were performed using R software (version 3.4.0; R Foundation for Statistical Computing, Vienna, Austria), and $P$ value $<0.05$ was considered to denote statistical significance. 


\section{Results}

\section{Patient characteristics in patients with and without the recurrence of AF}

In total, 254 patients with $\mathrm{AF}$ (mean age of 65.5 [SD =9.3]; $68.9 \%$ paroxysmal and $31.1 \%$ persistent; all first session) were included in this study (Table 1). All ablation procedures were successful. The median length of follow-up for censored cases was 730 days. AF recurred in 65 (25.6\%) patients during follow-up. Ln BNP was significantly greater in patients with the recurrence of $\mathrm{AF}$ than those without the recurrence of $\operatorname{AF}(P=0.006)$ and was an only variable which significantly differed between the groups (Table 1). Although statistically not significant, uses of $\beta$-blocker and loop diuretics were more frequent and $\mathrm{ln}$ sTM were lower in patients with the recurrence of AF than those without the recurrence of $\mathrm{AF}(P$ value $<0.10$, Table 1).

Because baseline ln BNP was significantly greater in patients with the recurrence of AF than those without the recurrence of $\mathrm{AF}$, the study patients were divided into two groups by the median concentration of BNP (groups with lower and higher levels of BNP) and then a probability of remaining free of the recurrence of $\mathrm{AF}$ after ablation procedure with a three-month blanking period was evaluated in the two groups. As a result, patient with the lower level of BNP had a greater probability of remaining free of the recurrence of AF than those with the higher level of BNP $(P$ value by log-rank test $=0.011)$ as shown in Fig. 1 . Two-year recurrence-free survival rates were $0.812(95 \%$ confidence interval $[\mathrm{CI}]=0.730-0.871)$ and $0.672(95 \%$ $\mathrm{CI}=0.578-0.749)$ in patients with the lower and higher levels of BNP, respectively.

\section{Associations of baseline variables with the recurrence of AF}

To determine associations of baseline variables with the recurrence of $\mathrm{AF}$, the univariate and multivariate $\mathrm{Cox}$ proportional hazards regression analyses. In the univariate Cox proportional hazards regression analyses, only ln BNP was significantly associated with the recurrence of $\mathrm{AF}$ (unadjusted $\mathrm{HR}=1.353,96 \% \mathrm{CI}=1.068-1.713$, $P=0.012$ ), whereas use of $\beta$-blocker, use of loop diuretics, and $\ln$ STM were not significantly associated with the recurrence of $\mathrm{AF}$ (unadjusted $\mathrm{HR}=1.582,96 \%$ $\mathrm{CI}=0.968-2.585, P=0.067$; unadjusted $\mathrm{HR}=1.603,96 \%$ $\mathrm{CI}=0.873-2.945, P=0.128$; unadjusted $\mathrm{HR}=0.447$, $96 \% \mathrm{CI}=0.180-1.107, P=0.082$, respectively) as shown in Table 2. In the multivariate Cox proportional hazards regression analysis, $\ln$ BNP remained significantly associated with the recurrence of $\mathrm{AF}$ (adjusted $\mathrm{HR}=1.286,96 \%$ $\mathrm{CI}=1.000-1.655, P=0.049)$ when tested with the use of $\beta$-blocker and ln sTM, $P$ values of which were $<0.10$ in the univariate Cox regression analysis (Table 2).

\section{Correlations between In BNP and the key risk variables}

Because ln BNP remained significantly and independently associated with the recurrence of AF, we performed a multiple regression analysis to test correlations between $\ln$ BNP and the key risk variables by the forced entry procedure. In a multivariate regression model controlling simultaneously for rhythm at blood collection, age, sex, type of AF, body mass index (BMI), eGFR, LAD, and LVEF, rhythm at blood collection, age, sex, LAD, and LVEF were significantly associated with the level of $\ln$ BNP (Table 3): specifically, $\mathrm{AF}$ at blood collection was significantly associated with the substantially increased level of $\ln$ BNP (adjusted $\beta=0.482$, $95 \% \mathrm{CI}=0.213-0.751, P$ value $<0.001)$.

\section{Subgroup analyses of risks of the recurrence of AF for In BNP}

We further performed subgroup analyses of risks of the recurrence of AF for $\ln$ BNP by dividing patients with the risk variables and the interaction effects of ln BNP with other risk variables, specifically with various combinations of rhythm status at blood collection and other risk variables because rhythm status at blood collection was significantly associated with substantially different levels of $\ln$ BNP (Table 3). Consequently, there was a significant interaction of $\ln$ BNP with sex and rhythm at blood collection ( $P$ for interaction $=0.011$ ) as shown in Table 4: higher $\ln$ BNP was significantly associated with an increased risk of the recurrence of $\mathrm{AF}$ in a subgroup of male sex with sinus rhythm at blood collection $(\mathrm{HR}=1.536,95 \% \mathrm{CI}=1.095-2.154, P$ value $=0.013$ ), but not in the other subgroups.

\section{Discussion}

In the present study, baseline ln BNP levels were significantly higher in patients with than without the recurrence of $\mathrm{AF}$, whereas there were no significant differences in clinical and echocardiographic variables, points of risk scores, and levels of biomarkers of endothelial dysfunction between patients with and without the recurrence of AF. During a 2-year follow-up period, patients with the higher level of ln BNP had a significantly higher recurrent rate of AF than those with the low level of ln BNP. Moreover, baseline ln BNP was significantly and independently associated with 
Table 1 Baseline characteristics of the study patients

\begin{tabular}{|c|c|c|c|c|}
\hline Variable & All patients $(n=254)$ & $\begin{array}{l}\text { Non- } \\
\text { recurrence } \\
(n=189)\end{array}$ & Recurrence $(n=65)$ & $P$ value \\
\hline Age, years & $65.5(9.3)$ & $66.0(9.2)$ & $64.0(9.4)$ & 0.141 \\
\hline Type of AF & & & & 0.438 \\
\hline Paroxysmal AF, $n(\%)$ & $175(68.9)$ & $133(70.4)$ & $42(64.6)$ & \\
\hline Persistent AF, $n(\%)$ & $79(31.1)$ & $56(29.6)$ & $23(35.4)$ & \\
\hline Sex, male, $n(\%)$ & $184(72.4)$ & 139 (73.5) & $45(69.2)$ & 0.522 \\
\hline BMI, $\mathrm{kg} / \mathrm{m}^{2}$ & $23.6(3.0)$ & $23.5(3.0)$ & $24.0(3.2)$ & 0.207 \\
\hline Mean blood pressure, $\mathrm{mmHg}$ & $92.9(13.0)$ & $92.9(12.5)$ & $93.0(14.4)$ & 0.948 \\
\hline Rhythm at blood sampling & & & & 0.106 \\
\hline SR, $n(\%)$ & $152(59.8)$ & $119(63.0)$ & $33(50.8)$ & \\
\hline $\mathrm{AF}, n(\%)$ & $102(40.2)$ & $70(37.0)$ & $32(49.2)$ & \\
\hline Current smoker, $n(\%)$ & $21(8.3)$ & $16(8.5)$ & $5(7.7)$ & 1.000 \\
\hline $\mathrm{CHADS}_{2}$ score & $1.0(1.0-2.0)$ & $1.0(1.0-2.0)$ & $1.0(1.0-2.0)$ & 0.170 \\
\hline $\mathrm{CHA}_{2} \mathrm{DS}_{2}$-VASc score & $2.0(1.0-3.0)$ & $2.0(1.0-3.0)$ & $2.0(1.0-3.0)$ & 0.271 \\
\hline APPLE score & $1.0(1.0-2.0)$ & $1.0(1.0-2.0)$ & $2.0(1.0-3.0)$ & 0.481 \\
\hline History of HF, $n(\%)$ & $34(13.4)$ & $22(11.6)$ & $12(18.5)$ & 0.204 \\
\hline History of HT, $n(\%)$ & $144(56.7)$ & $110(58.2)$ & $34(52.3)$ & 0.469 \\
\hline History of DM, $n(\%)$ & $32(12.6)$ & $27(14.3)$ & $5(7.7)$ & 0.198 \\
\hline History of stroke/TIA, $n(\%)$ & $23(9.1)$ & $19(10.1)$ & $4(6.2)$ & 0.456 \\
\hline History of vascular disease, $n(\%)$ & $13(5.1)$ & $10(5.3)$ & $3(4.6)$ & 1.000 \\
\hline $\mathrm{eGFR}, \mathrm{mL} / \mathrm{min} / 1.73 \mathrm{~m}^{2}$ & $80.4(21.7)$ & $80.4(20.9)$ & $80.3(24.1)$ & 0.986 \\
\hline $\mathrm{LAD}, \mathrm{mm}$ & $39.9(6.8)$ & $39.7(6.5)$ & $40.6(7.7)$ & 0.357 \\
\hline LVEF, \% & $62.3(9.1)$ & $62.4(9.3)$ & $62.0(8.8)$ & 0.730 \\
\hline \multicolumn{5}{|l|}{ Medications } \\
\hline Type of anticoagulants & & & & 0.273 \\
\hline VKA, $n(\%)$ & $48(18.9)$ & $39(20.6)$ & $9(13.8)$ & \\
\hline DOAC, $n(\%)$ & $206(81.1)$ & $150(79.4)$ & $56(86.2)$ & \\
\hline Acetylsalicylic acid, $n(\%)$ & $16(6.3)$ & $12(6.3)$ & $4(6.2)$ & 1.000 \\
\hline ACEI/ARB, $n(\%)$ & $104(40.9)$ & $80(42.3)$ & $24(36.9)$ & 0.468 \\
\hline$\beta$-blocker, $n(\%)$ & $84(33.1)$ & $56(29.6)$ & $28(43.1)$ & 0.066 \\
\hline $\mathrm{CCB}, n(\%)$ & $83(32.7)$ & $64(33.9)$ & $19(29.2)$ & 0.542 \\
\hline Digitalis, $n(\%)$ & $12(4.7)$ & $9(4.8)$ & $3(4.6)$ & 1.000 \\
\hline Loop diuretics, $n(\%)$ & $35(13.8)$ & $22(11.6)$ & $13(20.0)$ & 0.099 \\
\hline Aldosterone antagonist, $n(\%)$ & $14(5.5)$ & $9(4.8)$ & $5(7.7)$ & 0.358 \\
\hline Statin, $n(\%)$ & $53(20.9)$ & $40(21.2)$ & $13(20.0)$ & 1.000 \\
\hline $\mathrm{NCB}, n(\%)$ & $100(39.4)$ & $69(36.5)$ & $31(47.7)$ & 0.141 \\
\hline Bepridil, $n(\%)$ & $20(7.9)$ & $13(6.9)$ & $7(10.8)$ & 0.299 \\
\hline Amiodarone, $n(\%)$ & $11(4.3)$ & $7(3.7)$ & $4(6.2)$ & 0.480 \\
\hline $\ln \mathrm{BNP}$ & $4.3(1.1)$ & $4.2(1.1)$ & $4.6(1.0)$ & 0.006 \\
\hline $\ln \mathrm{sTM}$ & $0.95(0.27)$ & $0.97(0.28)$ & $0.90(0.26)$ & 0.079 \\
\hline ln sELAM1 & $3.3(0.4)$ & $3.3(0.4)$ & $3.3(0.5)$ & 0.870 \\
\hline ln sICAM1 & $5.1(0.4)$ & $5.1(0.4)$ & $5.2(0.4)$ & 0.162 \\
\hline ln sVCAM1 & $6.7(0.3)$ & $6.7(0.3)$ & $6.7(0.3)$ & 0.363 \\
\hline VWF activity, \% & $166.3(77.4)$ & 170.4 (77.2) & 154.4 (77.1) & 0.151 \\
\hline
\end{tabular}

The values are presented as number (\%), mean (standard deviation), or median (interquartile range)

$A C E$ angiotensin converting enzyme, $A F$ atrial fibrillation, $A R B$ angiotensin receptor blocker, $B M I$ body mass index, $B N P$ brain natriuretic peptide, $C C B$ calcium channel blocker, $D M$ diabetes mellitus, DOAC direct oral anticoagulant, $e G F R$ estimated glomerular filtration rate, $H F$ heart failure, $H T$ hypertension, $L A D$ left atrial diameter, $L V E F$ left ventricular ejection fraction, $N C B$ natrium channel blocker, $s E L A M 1$ soluble endothelial cell-leukocyte adhesion molecules-1, sICAMI soluble intercellular adhesion molecule-1, SR sinus rhythm; sTM = soluble thrombomodulin; sVCAM1 = soluble vascular cell adhesion molecule-1, TIA transient ischemic attack, VKA vitamin $\mathrm{K}$ antagonist, $V W F$ von Willebrand factor 


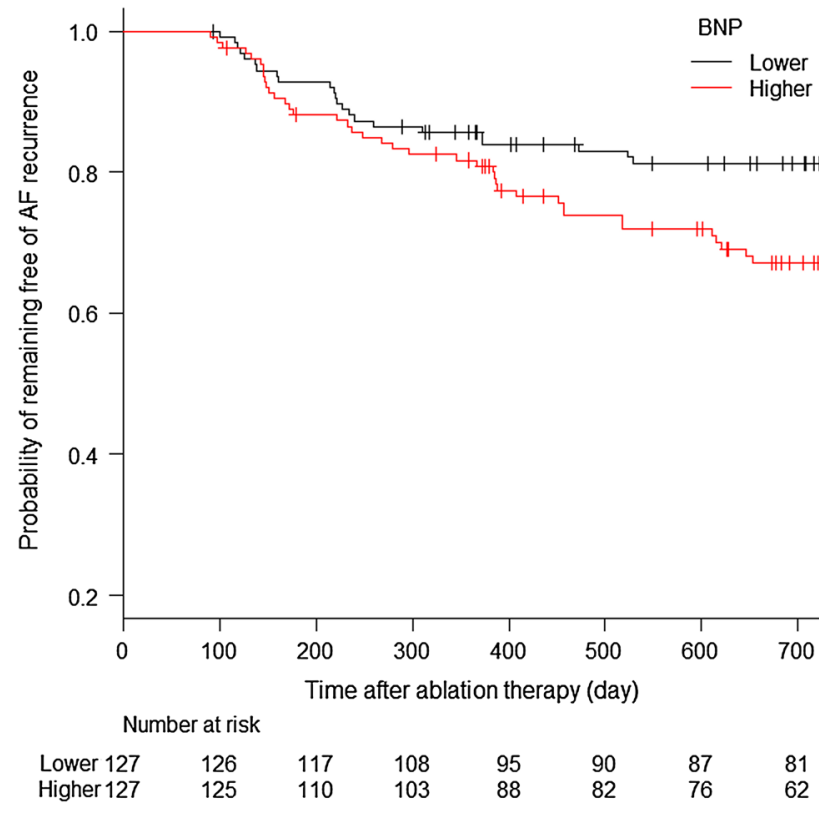

Fig. 1 Probability of remaining free of the recurrence of AF in patients with the lower and higher levels of BNP. Patients were divided into two groups by the median concentration of BNP. Patient with lower level of BNP had a greater probability of remaining free of the recurrence of AF than those with higher level of BNP ( $P$ value by $\log$-rank test $=0.011$ ). Two-year recurrence-free survival rates were $0.812(95 \% \mathrm{CI}=0.730-0.871)$ and $0.672(95 \% \mathrm{CI}=0.578$ 0.749 ) in patients with the lower and higher levels of BNP, respectively. $B N P$ brain natriuretic peptide

the recurrence of $\mathrm{AF}$ in the univariate and multivariate $\mathrm{Cox}$ regression analyses. Furthermore, baseline ln BNP levels were significantly associated with rhythm at blood collection, age, sex, and LAD, and LVEF. Finally, the subgroup analyses showed a significant interaction of ln BNP with rhythm status at blood collection and sex difference.

\section{Baseline clinical variables and scoring systems in the recurrence of $\mathrm{AF}$}

Many observational studies have reported predictors of the recurrence of $\mathrm{AF}$ after catheter ablation including the key risk variables [25]. Persistent $\mathrm{AF}$ and $\mathrm{LAD}$, both of which are related to atrial remodeling $[11,12]$, are most consistently recognized as important baseline predictors for the recurrence of AF [25]. A study showed that the APPLE score for the prediction of rhythm outcomes after catheter ablation of AF, which comprises age, type of AF, renal function, $\mathrm{LAD}$, and LVEF, had a better prediction of the recurrence of AF than $\mathrm{CHADS}_{2}$ and $\mathrm{CHA}_{2} \mathrm{DS}_{2}$-VASc scores [17]. However, in this study, above-mentioned baseline clinical variables, $\mathrm{CHADS}_{2}, \mathrm{CHA}_{2} \mathrm{DS}_{2}$-VASc, APPLE scores were not significantly different between patients with and without the recurrence of AF. Mean age of patients enrolled in this study was 65.5 years, whereas those of patients in other studies to identify predictors of late recurrence after AF ablation, to evaluate the values of $\mathrm{CHADS}_{2}, \mathrm{CHA}_{2} \mathrm{DS}_{2}$-VASc, and the APPLE scores were 57-61 years old [16,17,25]. Furthermore, BMI and LAD of patients in this study were smaller, a period of follow-up longer than those of patients in other studies, and races of patients differed between studies. Therefore, these differences between the current study and other studies may have caused inconsistent results of predictive values of baseline clinical variables and scoring systems for the recurrence of AF.

\section{Biomarkers in the recurrence of $\mathrm{AF}$}

Inflammation and oxidative stress have been reported as the etiology of AF development [8-10] and biomarkers of endothelial dysfunction caused by inflammatory, oxidative stress have been reported to be associated with risk of incident AF [20-24]; however, an association between pre-ablation concentrations of endothelial dysfunction biomarkers and the recurrence of AF has not yet been investigated. In the current study, we found no significant endothelial dysfunction biomarkers associated with risk of the recurrence
Table 2 Univariate and multivariate Cox regression analyses

\begin{tabular}{|c|c|c|c|c|c|c|}
\hline \multirow[t]{2}{*}{ Variable } & \multicolumn{3}{|l|}{ Univariate } & \multicolumn{3}{|l|}{ Multivariate } \\
\hline & Unadjusted HR & $95 \% \mathrm{CI}$ & $P$ value & Adjusted HR & $95 \% \mathrm{CI}$ & $P$ value \\
\hline$\beta$-blocker (use $=1$ ) & 1.582 & $0.968-2.585$ & 0.067 & 1.345 & $0.804-2.251$ & 0.258 \\
\hline Loop diuretics $($ use $=1)$ & 1.603 & $0.873-2.945$ & 0.128 & not selected & & \\
\hline $\ln \mathrm{BNP}$ (per 1 increase) & 1.353 & $1.068-1.713$ & 0.012 & 1.2860 & $1.000-1.655$ & 0.049 \\
\hline ln sTM (per 1 increase) & 0.447 & $0.180-1.107$ & 0.082 & 0.4960 & $0.207-1.190$ & 0.116 \\
\hline
\end{tabular}

After performing univariate Cox regression analysis, variables with $P$ value $<0.10$ were further evaluated by multivariate Cox regression analysis

$B N P$ brain natriuretic peptide, $C I$ confidence interval, $H R$ hazard ratio, ln natural logarithm, $s T M$ soluble thrombomodulin 
Table 3 Linear regression analyses for $\ln \mathrm{BNP}$

\begin{tabular}{|c|c|c|c|c|}
\hline \multirow[t]{2}{*}{ Variables } & \multicolumn{2}{|l|}{ Single regression } & \multicolumn{2}{|l|}{ Multiple regression } \\
\hline & Unadjusted $\beta$ coefficient & $P$ value & Adjusted $\beta$ coefficient & $P$ value \\
\hline Rhythm at blood collection $(\mathrm{AF}=1, \mathrm{SR}=0)$ & $0.857(0.613$ to 1.101$)$ & $<0.001$ & $0.482(0.213$ to 0.751$)$ & $<0.001$ \\
\hline Age (per year increase) & $0.036(0.023$ to 0.050$)$ & $<0.001$ & $0.027(0.015$ to 0.040$)$ & $<0.001$ \\
\hline Sex $($ male $=1$, female $=0)$ & $-0.284(-0.574$ to 0.005$)$ & 0.054 & $-0.438(-0.722$ to -0.154$)$ & 0.003 \\
\hline Type of $\mathrm{AF}$ (persistent $\mathrm{AF}=1$, paroxysmal $\mathrm{AF}=0$ ) & 0.877 (0.617to 1.137$)$ & $<0.001$ & $0.125(-0.180$ to 0.430$)$ & 0.420 \\
\hline BMI (per kg/m² increase) & $0.007(-0.036$ to 0.050$)$ & 0.752 & $-0.035(-0.072$ to 0.001$)$ & 0.058 \\
\hline eGFR (per $\mathrm{mL} / \mathrm{min} / 1.73 \mathrm{~m}^{2}$ increase) & $-0.007(-0.013$ to -0.001$)$ & 0.015 & $-0.004(-0.009$ to 0.002$)$ & 0.226 \\
\hline LAD (per mm increase) & $0.074(0.057$ to 0.091$)$ & $<0.001$ & $0.049(0.030$ to 0.068$)$ & $<0.001$ \\
\hline LVEF (per \% increase) & $-0.031(-0.045$ to -0.017$)$ & $<0.001$ & $-0.023(-0.035$ to -0.011$)$ & $<0.001$ \\
\hline
\end{tabular}

Abbreviations are shown as in Table 1. In a multiple regression analysis, the regression coefficient estimate ( $\beta$ ) was adjusted for all other variables listed.

of AF. It has been reported that the risk associated with endothelial dysfunction for arrhythmia recurrence following catheter ablation was age-dependent and was higher in younger than older patients with AF [23]. Therefore, it is possible that baseline concentrations of endothelial dysfunction biomarkers have predictive values for the recurrence of $\mathrm{AF}$ in younger patients than those enrolled in the current study. Further study is needed to confirm this possibility.

Associations between natriuretic peptide and the recurrence of AF have been intensively studied. Meta-analyses have shown that the recurrence of AF was associated with higher pre-ablation concentrations of BNP than non-recurrence although results of the studies were significantly heterogeneous; however, such heterogeneities have not been fully explained $[18,19]$. In the current study, we found that baseline In BNP was significantly and independently associated with the recurrence of AF. We also found that AF at blood collection was significantly associated with the substantially increased level of ln BNP. Moreover, the subgroup analyses showed a significant interaction of ln BNP with sex and rhythm at blood collection, which may explain the heterogeneities between studies to test associations between BNP and the recurrence of AF [18,19]. Taken together, in patients with nonvalvular AF, baseline BNP was suggested as a useful biomarker for the risk of late recurrence of $\mathrm{AF}$ after ablation; however, there is a need to be careful while using BNP as a biomarker for the recurrence of AF by taking account of the effects of rhythm status at blood collection and sex difference.

\section{Study limitations}

Several limitations of our study need to be considered. This study was performed in a single center, which may have resulted in a selection bias: indeed, BMI and LAD of patients in this study were smaller, and age was higher than those of patients in other studies. Asymptomatic episodes of AF may have been missed. We did not evaluate the responses of biomarkers to ablation therapy. We were unable to establish causal relationships between biomarker concentrations and the recurrence of AF because of a prospective observational study. However, our study also had several strengths, including a period of follow-up longer than other studies, deep and systematical evaluation of associations of the risk scores, biomarkers and atrial remodeling with the recurrence of $\mathrm{AF}$, which allowed us to recognize the usefulness of BNP as a predictor of recurrence after ablation treatment of atrial fibrillation and at the same time to recognize the attention at that time.

\section{Conclusions}

In this study, baseline levels of BNP, but not those of biomarkers of endothelial dysfunction or points of risk scoring systems, were independently associated with the recurrence of $\mathrm{AF}$ after radiofrequency catheter ablation. Baseline ln BNP levels were significantly associated with rhythm at blood collection, age, sex, and LAD, and LVEF, and the subgroup analyses showed significant interactions of $\ln$ BNP with sex, and rhythm at blood collection. These results suggest that pre-ablation levels of ln BNP are useful to evaluate the risk of AF recurrence after ablation; however, there is a need to be careful while using BNP as a biomarker for the risk of AF recurrence by taking account of the effects of rhythm status at blood collection and sex difference. 
Table 4 Subgroup analyses of hazard ratios of $\ln$ BNP for the recurrence of atrial fibrillation

\begin{tabular}{|c|c|c|c|c|}
\hline Subgroup & Recurrence, $n(\%)$ & Hazard ratio $(95 \% \mathrm{CI})$ of $\ln \mathrm{BNP}$ & $P$ value & $P$ for interaction \\
\hline Rhythm at blood collection & & & & 0.449 \\
\hline Sinus rhythm $(n=152)$ & $33(21.7 \%)$ & $1.397(1.022-1.911)$ & 0.036 & \\
\hline Atrial fibrillation $(n=102)$ & $32(31.4 \%)$ & $1.153(0.737-1.806)$ & 0.533 & \\
\hline Age & & & & 0.328 \\
\hline$<65(n=105)$ & $29(27.6 \%)$ & $1.230(0.872-1.734)$ & 0.238 & \\
\hline$\geq 65(n=149)$ & $36(24.2 \%)$ & $1.567(1.126-2.181)$ & 0.008 & \\
\hline Sex & & & & 0.791 \\
\hline Male $(n=184)$ & $45(24.5 \%)$ & $1.372(1.036-1.818)$ & 0.027 & \\
\hline Female $(n=70)$ & $20(28.6 \%)$ & $1.270(0.806-2.000)$ & 0.303 & \\
\hline Type of AF & & & & 0.666 \\
\hline Paroxysmal AF $(n=175)$ & $42(24.0 \%)$ & $1.415(1.076-1.861)$ & 0.013 & \\
\hline Persistent AF $(n=79)$ & $23(29.1 \%)$ & $1.271(0.710-2.275)$ & 0.419 & \\
\hline BMI & & & & 0.128 \\
\hline$<25 \mathrm{~kg} / \mathrm{m}^{2}(n=172)$ & $40(23.3 \%)$ & $1.204(0.902-1.606)$ & 0.207 & \\
\hline$\geq 25 \mathrm{~kg} / \mathrm{m}^{2}(n=82)$ & $25(30.5 \%)$ & $1.821(1.143-2.898)$ & 0.012 & \\
\hline eGFR & & & & 0.375 \\
\hline$\geq 60 \mathrm{ml} / \mathrm{min} / 1.78 \mathrm{~m}^{2}(n=216)$ & $55(25.5 \%)$ & $1.297(0.999-1.684)$ & 0.051 & \\
\hline$<60 \mathrm{ml} / \mathrm{min} / 1.78 \mathrm{~m}^{2}(n=38)$ & $10(26.3 \%)$ & $1.790(0.951-1.684)$ & 0.071 & \\
\hline LAD & & & & 0.443 \\
\hline$<40 \mathrm{~mm}(n=129)$ & $28(21.7 \%)$ & $1.213(0.855-1.721)$ & 0.280 & \\
\hline$\geq 40 \mathrm{~mm}(n=125)$ & $37(29.6 \%)$ & $1.467(1.029-2.090)$ & 0.034 & \\
\hline LVEF & & & & 0.863 \\
\hline$\geq 50 \%(n=227)$ & $58(25.6)$ & $1.398(1.0861 .800)$ & 0.009 & \\
\hline$<50 \%(n=27)$ & $7(25.9)$ & $1.294(0.4313 .880)$ & 0.646 & \\
\hline Age and rhythm at blood collection & & & & 0.583 \\
\hline Age $<65$ with SR $(n=61)$ & $16(26.2 \%)$ & $1.228(0.815-1.851)$ & 0.326 & \\
\hline Age $<65$ with AF $(n=44)$ & $13(29.5 \%)$ & $1.341(0.538-3.342)$ & 0.529 & \\
\hline Age $\geq 65$ with SR $(n=91)$ & $17(18.7 \%)$ & $1.867(1.156-3.015)$ & 0.011 & \\
\hline Age $\geq 65$ with AF $(n=58)$ & $19(32.8)$ & $1.105(0.635-1.922)$ & 0.724 & \\
\hline Sex and rhythm at blood collection & & & & 0.011 \\
\hline Male with SR $(n=104)$ & $25(24.0 \%)$ & $1.536(1.095-2.154)$ & 0.013 & \\
\hline Male with AF $(n=80)$ & $20(25.0 \%)$ & $1.221(0.671-2.223)$ & 0.513 & \\
\hline Female with SR $(n=48)$ & $8(16.7 \%)$ & $0.999(0.432-2.311)$ & 0.999 & \\
\hline Female with AF $(n=22)$ & $12(54.5 \%)$ & $0.743(0.330-1.675)$ & 0.474 & \\
\hline Type of AF and rhythm at blood collection & & & & 0.436 \\
\hline Paroxysmal AF with SR $(n=141)$ & $30(21.3 \%)$ & $1.391(0.997-1.943)$ & 0.052 & \\
\hline Paroxysmal AF with AF $(n=34)$ & $12(35.3)$ & $1.162(0.641-2.108)$ & 0.621 & \\
\hline Persistent AF with SR $(n=11)$ & $3(27.3 \%)$ & $1.920(0.353-10.430)$ & 0.450 & \\
\hline Persistent AF with AF $(n=68)$ & $20(29.4 \%)$ & $1.187(0.628-2.244)$ & 0.597 & \\
\hline BMI and rhythm at blood collection & & & & 0.640 \\
\hline BMI $<25 \mathrm{~kg} / \mathrm{m}^{2} \mathrm{~mm}$ with SR $(n=109)$ & $23(21.1 \%)$ & $1.147(0.791-1.664)$ & 0.470 & \\
\hline $\mathrm{BMI}<25 \mathrm{~kg} / \mathrm{m}^{2} \mathrm{~mm}$ with $\mathrm{AF}(n=63)$ & $17(27.0 \%)$ & $1.225(0.698-2.151)$ & 0.479 & \\
\hline $\mathrm{BMI} \geq 25 \mathrm{~kg} / \mathrm{m}^{2} \mathrm{~mm}$ with SR $(n=43)$ & $10(23.2 \%)$ & $2.269(1.170-4.401)$ & 0.015 & \\
\hline $\mathrm{BMI} \geq 25 \mathrm{~kg} / \mathrm{m}^{2} \mathrm{~mm}$ with AF $(n=39)$ & $15(38.5 \%)$ & $1.010(0.437-2.335)$ & 0.982 & \\
\hline eGFR and rhythm at blood collection & & & & 0.472 \\
\hline $\mathrm{eGFR} \geq 60 \mathrm{ml} / \mathrm{min} / 1.78 \mathrm{~m}^{2} \mathrm{~mm}$ with SR $(n=130)$ & $28(21.5 \%)$ & $1.230(0.881-1.716)$ & 0.225 & \\
\hline $\mathrm{eGFR} \geq 60 \mathrm{ml} / \mathrm{min} / 1.78 \mathrm{~m}^{2} \mathrm{~mm}$ with $\mathrm{AF}(n=86)$ & $27(31.3 \%)$ & $1.258(0.742-2.131)$ & 0.394 & \\
\hline eGFR $<60 \mathrm{ml} / \mathrm{min} / 1.78 \mathrm{~m}^{2} \mathrm{~mm}$ with SR $(n=22)$ & $5(22.7 \%)$ & $3.702(1.135-12.080)$ & 0.030 & \\
\hline eGFR $<60 \mathrm{ml} / \mathrm{min} / 1.78 \mathrm{~m}^{2} \mathrm{~mm}$ with $\mathrm{AF}(n=16)$ & $5(31.3 \%)$ & $1.000(0.281-3.557)$ & 1.000 & \\
\hline LAD and rhythm at blood collection & & & & 0.374 \\
\hline
\end{tabular}


Table 4 (continued)

\begin{tabular}{|c|c|c|c|c|}
\hline Subgroup & Recurrence, $n(\%)$ & Hazard ratio $(95 \% \mathrm{CI})$ of $\ln \mathrm{BNP}$ & $P$ value & $P$ for interaction \\
\hline LAD $<40 \mathrm{~mm}$ with SR $(n=100)$ & $19(19.0 \%)$ & $1.034(0.684-1.562)$ & 0.874 & \\
\hline LAD < 40 mm with AF $(n=29)$ & $9(31.0 \%)$ & $2.033(0.599-6.904)$ & 0.255 & \\
\hline LAD $\geq 40 \mathrm{~mm}$ with SR $(n=52)$ & $14(26.9 \%)$ & $2.382(1.305-4.348)$ & 0.005 & \\
\hline $\mathrm{LAD} \geq 40 \mathrm{~mm}$ with $\mathrm{AF}(n=73)$ & $23(31.5 \%)$ & $0.994(0.590-1.675)$ & 0.981 & \\
\hline LVEF and rhythm at blood collection & & & & 0.876 \\
\hline LVEF $\geq 50 \%$ mm with SR $(n=141)$ & $30(21.3)$ & $1.394(0.997-1.949)$ & 0.052 & \\
\hline LVEF $\geq 50 \%$ mm with AF $(n=86)$ & $28(32.6)$ & $1.230(0.765-1.977)$ & 0.392 & \\
\hline LVEF $<50 \%$ mm with SR $(n=11)$ & $3(27.3)$ & $1.487(0.353-6.257)$ & 0.589 & \\
\hline LVEF $<50 \%$ mm with AF $(n=16)$ & $4(25.0)$ & $0.933(0.137-6.338)$ & 0.944 & \\
\hline
\end{tabular}

Abbreviations are shown as in Table 1.

Acknowledgements This work was supported by a Grant from the Faculty of Medicine, Tottori University, Yonago, Japan. We thank Dr. Trish Reynolds, MBBS, FRACP, from Edanz Group for editing a draft of this manuscript.

Funding Funding was provided by Tottori University.

\section{Compliance with ethical standards}

Conflict of interest The authors have no conflict of interest to disclose.

Ethical approval All procedures performed in studies involving human participants were in accordance with the ethical standards of the institutional and/or national research committee and with the 1964 Helsinki declaration and its later amendments or comparable ethical standards.

Open Access This article is distributed under the terms of the Creative Commons Attribution 4.0 International License (http://creativecommons.org/licenses/by/4.0/), which permits unrestricted use, distribution, and reproduction in any medium, provided you give appropriate credit to the original author(s) and the source, provide a link to the Creative Commons license, and indicate if changes were made.

\section{References}

1. Go AS, Hylek EM, Phillips KA, Chang Y, Henault LE, Selby JV, Singer DE (2001) Prevalence of diagnosed atrial fibrillation in adults: national implications for rhythm management and stroke prevention: the AnTicoagulation and Risk Factors in Atrial Fibrillation (ATRIA) Study. JAMA 285:2370-2375

2. Stewart S, Hart CL, Hole DJ, McMurray JJV (2002) A populationbased study of the long-term risks associated with atrial fibrillation: 20-year follow-up of the Renfrew/Paisley study. Am J Med 113:359-364

3. LaPar DJ, Speir AM, Crosby IK, Fonner E Jr., Brown M, Rich JB, Quader M, Kern JA, Kron IL Ailawadi G (2014) Postoperative atrial fibrillation significantly increases mortality, hospital readmission, and hospital costs. Ann Thorac Surg 98:527-533 (discussion 533)

4. Haissaguerre M, Jais P, Shah DC, Takahashi A, Hocini M, Quiniou G, Garrigue S, Le Mouroux A, Le Metayer P, Clementy J
(1998) Spontaneous initiation of atrial fibrillation by ectopic beats originating in the pulmonary veins. N Engl J Med 339:659-666

5. Calkins H, Hindricks G, Cappato R, Kim YH, Saad EB, Aguinaga L, Akar JG, Badhwar V, Brugada J, Camm J, Chen PS, Chen SA, Chung MK, Nielsen JC, Curtis AB, Davies DW, Day JD, d'Avila A, de Groot N, Di Biase L, Duytschaever M, Edgerton JR, Ellenbogen KA, Ellinor PT, Ernst S, Fenelon G, Gerstenfeld EP, Haines DE, Haissaguerre M, Helm RH, Hylek E, Jackman WM, Jalife J, Kalman JM, Kautzner J, Kottkamp H, Kuck KH, Kumagai K, Lee R, Lewalter T, Lindsay BD, Macle L, Mansour M, Marchlinski FE, Michaud GF, Nakagawa H, Natale A, Nattel S, Okumura K, Packer D, Pokushalov E, Reynolds MR, Sanders P, Scanavacca M, Schilling R, Tondo C, Tsao HM, Verma A, Wilber DJ, Yamane T (2017) 2017 HRS/EHRA/ECAS/APHRS/ SOLAECE expert consensus statement on catheter and surgical ablation of atrial fibrillation. Heart Rhythm 14:e275-e444

6. Kuck KH, Hoffmann BA, Ernst S, Wegscheider K, Treszl A, Metzner A, Eckardt L, Lewalter T, Breithardt G, Willems S (2016) Impact of complete versus incomplete circumferential lines around the pulmonary veins during catheter ablation of paroxysmal atrial fibrillation: results from the Gap-Atrial Fibrillation-German Atrial Fibrillation Competence Network 1 Trial. Circ Arrhythm Electrophysiol 9:e003337

7. Zaman JAB, Baykaner T, Clopton P, Swarup V, Kowal RC, Daubert JP, Day JD, Hummel J, Schricker AA, Krummen DE, Mansour M, Tomassoni GF, Wheelan KR, Vishwanathan M, Park S, Wang PJ, Narayan SM, Miller JM (2017) Recurrent post-ablation paroxysmal atrial fibrillation shares substrates with persistent atrial fibrillation : an 11-center study. JACC Clin Electrophysiol 3:393-402

8. Sardu C, Santulli G, Santamaria M, Barbieri M, Sacra C, Paolisso P, D'Amico F, Testa N, Caporaso I, Paolisso G, Marfella R, Rizzo MR (2017) Effects of alpha lipoic acid on multiple cytokines and biomarkers and recurrence of atrial fibrillation within 1 year of catheter ablation. Am J Cardiol 119:1382-1386

9. Samman Tahhan A, Sandesara PB, Hayek SS, Alkhoder A, Chivukula K, Hammadah M, Mohamed-Kelli H, O’Neal WT, Topel M, Ghasemzadeh N, Ko YA, Aida H, Gafeer M, Sperling L, Vaccarino V, Liang Y, Jones DP, Quyyumi AA (2017) Association between oxidative stress and atrial fibrillation. Heart Rhythm 14:1849-1855

10. Xie W, Santulli G, Reiken SR, Yuan Q, Osborne BW, Chen BX, Marks AR (2015) Mitochondrial oxidative stress promotes atrial fibrillation. Sci Rep 5:11427

11. Santulli G, D'Ascia SL, D'Ascia C (2012) Development of atrial fibrillation in recipients of cardiac resynchronization 
therapy: the role of atrial reverse remodelling. Can J Cardiol 28(245):e217 (author reply 245 e217-248)

12. D'Ascia SL, D'Ascia C, Marino V, Lombardi A, Santulli R, Chiariello M, Santulli G (2011) Cardiac resynchronisation therapy response predicts occurrence of atrial fibrillation in non-ischaemic dilated cardiomyopathy. Int J Clin Pract 65:1149-1155

13. Kornej J, Hindricks G, Kosiuk J, Arya A, Sommer P, Husser D, Rolf S, Richter S, Piorkowski C, Gaspar T, Lip GY, Bollmann A (2013) Renal dysfunction, stroke risk scores (CHADS2, CHA2DS2-VASc, and R2CHADS2), and the risk of thromboembolic events after catheter ablation of atrial fibrillation: the Leipzig Heart Center AF Ablation Registry. Circ Arrhythm Electrophysiol 6:868-874

14. Letsas KP, Efremidis M, Giannopoulos G, Deftereos S, Lioni L, Korantzopoulos P, Vlachos K, Xydonas S, Kossyvakis C, Sideris A (2014) CHADS2 and CHA2DS2-VASc scores as predictors of left atrial ablation outcomes for paroxysmal atrial fibrillation. Europace 16:202-207

15. Jacobs V, May HT, Bair TL, Crandall BG, Cutler M, Day JD, Weiss JP, Osborn JS, Muhlestein JB, Anderson JL, Mallender C, Bunch TJ (2015) The impact of risk score (CHADS2 versus CHA2DS2-VASc) on long-term outcomes after atrial fibrillation ablation. Heart Rhythm 12:681-686

16. Kornej J, Hindricks G, Kosiuk J, Arya A, Sommer P, Husser D, Rolf S, Richter S, Huo Y, Piorkowski C, Bollmann A (2014) Comparison of CHADS2, R2CHADS2, and CHA2DS2-VASc scores for the prediction of rhythm outcomes after catheter ablation of atrial fibrillation: the Leipzig Heart Center AF Ablation Registry. Circ Arrhythm Electrophysiol 7:281-287

17. Kornej J, Hindricks G, Shoemaker MB, Husser D, Arya A, Sommer P, Rolf S, Saavedra P, Kanagasundram A, Patrick Whalen S, Montgomery J, Ellis CR, Darbar D, Bollmann A (2015) The APPLE score: a novel and simple score for the prediction of rhythm outcomes after catheter ablation of atrial fibrillation. Clin Res Cardiol 104:871-876

18. Zhang Y, Chen A, Song L, Li M, Chen Y, He B (2016) Association between baseline natriuretic peptides and atrial fibrillation recurrence after catheter ablation. Int Heart J 57:183-189

19. Jiang H, Wang W, Wang C, Xie X, Hou Y (2017) Association of pre-ablation level of potential blood markers with atrial fibrillation recurrence after catheter ablation: a meta-analysis. Europace 19:392-400

20. Willeit K, Pechlaner R, Willeit P, Skroblin P, Paulweber B, Schernthaner C, Toell T, Egger G, Weger S, Oberhollenzer M,
Kedenko L, Iglseder B, Bonora E, Schett G, Mayr M, Willeit J, Kiechl S (2017) Association between vascular cell adhesion molecule 1 and atrial fibrillation. JAMA Cardiol 2:516-523

21. Conen D, Ridker PM, Everett BM, Tedrow UB, Rose L, Cook NR, Buring JE, Albert CM (2010) A multimarker approach to assess the influence of inflammation on the incidence of atrial fibrillation in women. Eur Heart J 31:1730-1736

22. Krishnamoorthy S, Khoo CW, Lim HS, Lane DA, Pignatelli P, Basili S, Violi F, Lip GY (2013) Prognostic role of plasma von Willebrand factor and soluble E-selectin levels for future cardiovascular events in a 'real-world' community cohort of patients with atrial fibrillation. Eur J Clin Invest 43:1032-1038

23. Weymann A, Sabashnikov A, Ali-Hasan-Al-Saegh S, Popov AF, Jalil Mirhosseini S, Baker WL, Lotfaliani M, Liu T, Dehghan H, Yavuz S, de Oliveira Sa MP, Jang JS, Zeriouh M, Meng L, D’Ascenzo F, Deshmukh AJ, Biondi-Zoccai G, Dohmen PM, Calkins H, Cardiac Surgery and Cardiology-Group ImcscGroup IM (2017) Predictive role of coagulation, fibrinolytic, and endothelial markers in patients with atrial fibrillation, stroke, and thromboembolism: a meta-analysis, meta-regression, and systematic review. Med Sci Monit Basic Res 23:97-140

24. Conway DS, Heeringa J, Van Der Kuip DA, Chin BS, Hofman A, Witteman JC, Lip GY (2003) Atrial fibrillation and the prothrombotic state in the elderly: the Rotterdam Study. Stroke 34:413-417

25. D'Ascenzo F, Corleto A, Biondi-Zoccai G, Anselmino M, Ferraris F, di Biase L, Natale A, Hunter RJ, Schilling RJ, Miyazaki S, Tada H, Aonuma K, Yenn-Jiang L, Tao H, Ma C, Packer D, Hammill S, Gaita F (2013) Which are the most reliable predictors of recurrence of atrial fibrillation after transcatheter ablation?: a meta-analysis. Int J Cardiol 167:1984-1989

26. Matsuo S, Imai E, Horio M, Yasuda Y, Tomita K, Nitta K, Yamagata K, Tomino Y, Yokoyama H, Hishida A (2009) Revised equations for estimated GFR from serum creatinine in Japan. Am J Kidney Dis 53:982-992

27. Kondo T, Miake J, Kato M, Ogura K, Iitsuka K, Yamamoto K (2016) Impact of postprocedural antiarrhythmic drug therapy with bepridil on maintaining sinus rhythm after catheter ablation for persistent atrial fibrillation. J Cardiol 68:229-235

28. Matsuzawa Y, Suleiman M, Guddeti RR, Kwon TG, Monahan KH, Lerman LO, Friedman PA, Lerman A (2016) Age-dependent predictive value of endothelial dysfunction for arrhythmia recurrence following pulmonary vein isolation. J Am Heart Assoc 5:e003183 